\title{
Growth of probiotic Lactobacillus rhamnosus GR-1 using saccharified oil palm mesocarp fibre as affected by saccharification time and fermentation time
}

\author{
${ }^{1}$ Mohd, N.H., ${ }^{2, *}$ Maskat, M.Y., ${ }^{1,3}$ Mackeen, M.M., ${ }^{2}$ Zaini, N.A.M., ${ }^{2}$ Sahilah, A.M. and \\ ${ }^{1}$ Sage, E.E. \\ ${ }^{1}$ Department of Chemical Sciences, Faculty of Science and Technology, Universiti Kebangsaan Malaysia, \\ Bangi, Selangor, Malaysia \\ ${ }^{2}$ Department of Food Sciences, Faculty of Science and Technology, Universiti Kebangsaan Malaysia, Bangi, \\ Selangor, Malaysia \\ ${ }^{3}$ Institute of Systems Biology (INBIOSIS), Universiti Kebangsaan Malaysia, Bangi, Selangor, Malaysia
}

\begin{abstract}
Article history:
Received: 31 December 2020

Received in revised form: 13

February 2021

Accepted: 29 May 2021

Available Online: 26 January 2022

\section{Keywords:}

Saccharification time,

Fermentation time,

Lactobacillus rhamnosus GR-

1 ,

Oil palm fibre
\end{abstract}

DOI:

https://doi.org/10.26656/fr.2017.6(1).723

\begin{abstract}
Abundant low-cost oil palm mesocarp fibre could serve as a potential feedstock for the production of oligosaccharides which may have prebiotic properties. Thus, a study was carried out to determine the ability of saccharified oil palm mesocarp fibre (OPMF) to support the growth of a probiotic microorganism (Lactobacillus rhamnosus GR-1). The saccharified OPMF was produced using different saccharification times (1, 3 and $6 \mathrm{hrs})$ while fermentation of the saccharified OPMF with L. rhamnosus GR-1 was carried out for 0,12 and 24 hrs. Growth of L. rhamnosus GR-1 was measured based on $\mathrm{OD}_{600}$ using a UV-spectrophotometer along with the $\mathrm{pH}$ of the growth media. The results showed a significantly higher $(\mathrm{p}<0.05)$ growth of L. rhamnosus GR-1 with increasing saccharification time and fermentation time. Increased saccharification time of up to $6 \mathrm{hrs}$ also resulted in a higher variety of oligosaccharides compared to 1 hour and significantly reduced $(\mathrm{p}<0.05) \mathrm{pH}$ of the growth media. The use of saccharified OPMF produced comparable growth of L. rhamnosus GR-1 with significantly lower $(\mathrm{p}<0.05) \mathrm{pH}$ compared to using fructooligosaccharide in the growth media. The results showed the ability of saccharified OPMF to support the growth of probiotic L. rhamnosus GR-1.
\end{abstract}

\section{Introduction}

The World Health Organization defines a probiotic as "live microorganisms that when administered in adequate amounts confer a health benefit on the host when ingested" (Williams and Hekmat, 2017; White and Hekmat, 2018). Examples of probiotic microorganisms include Lactobacillus rhamnosus, Lactobacillus plantarum (Asmariah et al., 2018), Lactobacillus salivarius, Lactobacillus reuteri (Shamsudin et al., 2019) as well as Bifidobacterium species (Williams and Hekmat, 2017). The growth and metabolic activity of probiotic bacteria such as lactobacilli can be selectively accelerated by various dietary carbohydrates that were not digested by the host (Leblanc et al., 2017). Prebiotics are defined as a selectively fermented ingredient that concedes specific changes, both in condition and/or activity in the gastrointestinal microflora, that bestow health benefits (White and Hekmat, 2018).

Nowadays, it is a great attraction to produce novel forms of prebiotic from readily available and renewable carbohydrate resources (Shi et al., 2018). Recently, there has been increased interest in the potential of oligosaccharides as prebiotics such as xylooligosaccharides, fructooligosaccharides (FOS), and several others (Dávila et al., 2019). An oligosaccharide is a molecule containing a low number of monosaccharide residues connected by glycosidic linkages (Nguyen and Haltrich, 2013). According to Patel and Goyal (2011), functional oligosaccharides are gaining outstanding popularity among the non-digestible carbohydrates, owing to their physiological benefits to the consumer. Moreover, they positively affect the composition and metabolic activity of the intestinal microflora and a daily moderate supplement of these non -digestible oligosaccharides stimulates mineral absorption especially $\mathrm{Ca}$ and $\mathrm{Mg}$ (Roberfroid et al., 2010; Kunova et al., 2012).

Biomass from plant material is the most abundant and widespread renewable raw material for sustainable development and can be employed as a source of 
polymeric and oligomeric carbohydrates (Gullon et al., 2009). Cellulose is a high molecular weight linear polymer composed of $\beta$-glucose (5000-10,000 units) and linked by $\beta-1,4$-glycosidic bonds (Srivastava et al., 2019). Enzymatic hydrolysis using cellulase from Trichoderma reesei, a mixture of endoglucanases, exoglucanases, and $\beta$-glucosidase, is widely used for the degradation of cellulose into soluble oligo glucan/ oligomers, cellobiose and glucose (Pasma et al., 2013). Cellulose from oil palm mesocarp fibre (OPMF) possibly can be depolymerised using enzymes to produce oligosaccharides through saccharification. About 80 million tonnes of oil palm biomass was produced in Malaysia in 2017. In addition, it was forecasted that the quantity of solid biomass from oil palm will reach 111 million tonnes a year by 2020 (MGCC, 2018). Moreover, approximately $11 \%$ of oil palm mesocarp fibre (OPMF) is generated from palm fruits after oil extraction. OPMF, also known as palm pressed fibre (PPF), is the biomass residue obtained after pressing the palm fruits for palm oil extraction (Nordin et al., 2013). Thus, it is a potential source of biomass that can be utilised for the production of valuable compounds (Pasma, Rusli and Maskat, 2019). However, in order for the saccharified OPMF to function as a prebiotic, it has to be shown to be able to support the growth of probiotic microorganisms.

Lactobacillus rhamnosus GR-1 was chosen for this study since it was known as the second most scientifically documented $L$. rhamnosus probiotic. It was discovered in 1981 in Kingston, Ontario (Westerik et al., 2018). L. rhamnosus GR-1 is a probiotic strain that is bile and acid resistant and also can survive the passage through the gastrointestinal tract. These properties made L. rhamnosus GR-1 exert a number of human health benefits such as the prevention of urinary tract infections and oral intake of GR-1 also provide benefits to the urogenital tract, the gut as well as respiratory tract (Westerik et al., 2018; White and Hekmat 2018; Figueroa-Gonzalez et al., 2019). Due to its properties, $L$. rhamnosus GR-1 has been attributed as one of the main probiotic strains that are suitable for applications in the production of yoghurt and fermented foods in Africa (Wekstrik et al., 2018). Meanwhile, Zare et al. (2012) reported that $L$. rhamnosus has been the main species used as a probiotic over the years.

Williams and Hekmat (2017) have described the addition of short-chain inulin, long-chain Inulin and oat have no adverse supplementation effects in the viability of $L$. rhamnosus GR-1, with $4 \%$ of short-chain inulin showing the highest viability. While, White and Hekmat (2018) were found that the fermentation of apple cider, grape and orange juice fortified with inulin fibre with $L$. rhamnosus GR-1 improved the viable bacterial counts that were greater than the minimum requirement of $10^{6}$ $\mathrm{CFU} / \mathrm{mL}$, to be classified as prebiotics. Other than that, results from the sensory evaluation indicated may be potential for probiotic fruit juices in the commercial market. A study conducted by Dunkley and Hekmat (2019) has studied the growth and viability of $L$. rhamnosus GR-1 in carrot juice (CJ), carrot apple juice $(\mathrm{CAJ})$, carrot orange juice (COJ) and carrot apple juice (CBJ) over $72 \mathrm{~h}$ of fermentation and 30 days storage at $4^{\circ} \mathrm{C}$. The result showed a significant microbial growth only juices $\mathrm{CJ}$ and $\mathrm{COJ}$ with a significant decline in $\mathrm{pH}$.

Due to its abundance, OPMF fibre has the potential to serve as a lower-cost cellulosic feedstock to produce oligosaccharides as an alternative source of prebiotic. As there is limited literature on the use of saccharified OPMF as feedstock for probiotics, this study was carried out to determine the ability of saccharified OPMF to support the growth of L. rhamnosus GR-1 which is a known probiotic as affected by saccharification time and also fermentation time.

\section{Materials and methods}

\subsection{Materials}

The oil palm mesocarp fibre (OPMF) was sourced from a local oil palm mill in Hulu Langat, Selangor, Malaysia. Acetonitrile, manganese (II) sulfate tetrahydrate and Tween- 80 were purchased from Merck and Co. (USA), while acetate buffer solution ( $\mathrm{pH} 4.0$ ) and di-potassium-hydrogen phosphate were obtained from R\&M Chemicals. Di-ammonium-hydrogen citrate, sodium acetate and magnesium sulphate were purchased from Chemiz, Malaysia. Other chemicals, sodium hydroxide $(\mathrm{NaOH})$, sodium acetate anhydride, ethanol $(95 \% \mathrm{v} / \mathrm{v})$, ethyl acetate and meat extract were purchased from Systerm, Malaysia. Meanwhile, dextran molecular weight ladder ( $\mathrm{Mw}$ 5000), ammonium acetate, 2aminobenzamide (2-AB), sodium cyanoborohydride, fructooligosaccharide (FOS), phosphate buffered saline (PBS), cysteine hydrochloride and enzyme cocktail Celluclast (1.5 L) from Trichoderma reesei (>700 units/ g) were obtained from Sigma Aldrich Co. (St. Louis MO, USA). Chemicals for probiotic medium preparation, Man -Rogosa-Sharpe (MRS) broth for microbiology with carbohydrate source was obtained from Fluka Analytical and MRS agar, bacteriological peptone, and yeast extract were purchased from Oxoid (Hampshire, UK). ManRogosa-Sharpe (MRS) liquid without carbohydrate source was prepared by dissolving $10 \mathrm{~g}$ of bacteriological peptone, $8 \mathrm{~g}$ of meat extract, $4 \mathrm{~g}$ of yeast extract, $1 \mathrm{~g}$ of di-potassium-hydrogen phosphate, $2 \mathrm{~g}$ of Tween-80, $2 \mathrm{~g}$ of di-ammonium-hydrogen citrate, $5 \mathrm{~g}$ of sodium acetate, $0.2 \mathrm{~g}$ of magnesium sulphate and $0.04 \mathrm{~g}$ of manganese (II) sulphate tetrahydrate per litre. The 
medium was autoclaved and stored at $4^{\circ} \mathrm{C}$ until further use.

\subsection{Preparation of carbohydrate substrates}

The mesocarp fibre was washed to remove foreign particles and dried in an oven at $80^{\circ} \mathrm{C}$ overnight (Pasma et al., 2019). Subsequently, the dried fibre was ground into approximately $0.25 \mathrm{~mm}$ particles, transferred into sealed plastic bags and stored at $4^{\circ} \mathrm{C}$ until used. The ground OPMF was deconstructed as according to Hassan et al. (2013) with slight modifications which involved pre-treatment using steam and $15 \% \mathrm{NaOH}$ solution.

Subsequently, the OPMF was subjected to enzymatic saccharification using a commercial enzyme cocktail (Celluclast $1.5 \mathrm{~L}$ ) in an incubator shaker (Wisecube wis $20)$ at $50^{\circ} \mathrm{C}, 120 \mathrm{rpm}$ (Tang et al., 2018). The saccharification time was varied at 1,3 and $6 \mathrm{hrs}$ to produce samples at different degrees of polymerisation (DP) ranging between 2 and 4. The saccharified OPMF was extracted by centrifugation $2147 \times g, 15$ mins (Thermo Scientific ${ }^{\mathrm{TM}}$ Sorvall ${ }^{\mathrm{TM}}$ model) and then dried using a rotary evaporator. The glucose units (GU) of saccharified OPMF was determined using highperformance liquid chromatography with fluorescence detection (HPLC-FD). Fluorescent labelling via chemical derivatisation with 2-aminobenzamide (2-AB) and the subsequent HPLC-FD analysis of saccharified OPMF samples were carried out as described previously (Woon et al., 2016; Jalaludin et al., 2017). The 2AB-labelled samples (10 $\mu \mathrm{L}$ of hydrolysate) were run on an HPLC instrument using an XBridge amide $(4.6 \times 250 \mathrm{~mm}$, particle size $3.5 \mu \mathrm{m})$ column with a gradient elution system of ammonium acetate $(\mathrm{pH} 3.5)$ and acetonitrile as reported by Woon et al. (2016). The chromatography system consists of a Waters 600 pump, autosampler Waters 2707 with a Waters 2745 model fluorescent detector set at the wavelengths of $360 \mathrm{~nm}$ wavelength (excitation) and $426 \mathrm{~nm}$ (emission).

\subsection{In vitro fermentation of saccharified OPMF using Lactobacillus rhamnosus}

The fermentation of saccharified OPMF using $L$. rhamnosus GR-1 was carried out according to the methods by Shi et al. (2018) and Mueller et al. (2016) with slight modifications. A fresh overnight culture of $L$. rhamnosus GR-1 was prepared in MRS broth with carbohydrate source (Fluka Analytical) at $37^{\circ} \mathrm{C}$ for 16 hrs at $180 \mathrm{rpm}$ using an incubator shaker (Wisecube wis 20 ) in aerobic condition and cell density was determined based on turbidity measurement as indicated by an increased $\mathrm{OD}_{600}$ value using UV-spectrophotometer (Spectronic 200, Thermo Scientific ${ }^{\mathrm{TM}}$ ). Subsequently, the cultured bacteria were collected by centrifugation at
$6708 \times g$ for 5 mins (Gryozen Mini, Korea) and the bacteria were washed two times in phosphate buffered saline (PBS) supplemented with cysteine hydrochloride to remove MRS broth residue. The cell amount for a final starting $\mathrm{OD}_{600}$ of 0.1 was determined. The bacteria $(1 \% \mathrm{v} / \mathrm{v})$ were resuspended in the MRS broth medium in the absence of any carbohydrate source. Subsequently, the fermentation was conducted in the presence of $1 \%$ (v/v) saccharide OPMF samples (1, 3 and $6 \mathrm{hrs})$ in a 100 $\mathrm{mL}$ Erlenmeyer flask with a final volume of $30 \mathrm{~mL}$. Aerobic fermentation of the saccharified OPMF was carried out for 0,12 and $24 \mathrm{hrs}$ at $37^{\circ} \mathrm{C}$ at $180 \mathrm{rpm}$ incubator shaker (Wisecube wis 20). The growth of $L$. rhamnosus GR-1 was measured based on $\mathrm{OD}_{600}$ using a UV-spectrophotometer. The negative control was incubated without sugar and FOS was chosen as a positive control. All experiments were conducted in triplicates.

\section{4 pH analysis}

The $\mathrm{pH}$ of all saccharified OPMF samples $(1,3$ and $6 \mathrm{hrs}$ ) was measured using Sartorius Basic PB-10 pH meter (Germany) after 0, 12 and 24 hrs of fermentation. An average of three replicates of each sample at each fermentation time was taken.

\subsection{Statistical analysis}

All data reported in this study was indicated as means \pm SD. To determine if there were significant differences in the growth of $L$. rhamnosus GR-1 a twoway ANOVA and Tukey test were performed using the statistical software JASP. Comparison of $\mathrm{pH}$ data was carried out using one-way ANOVA and Tukey test. The confidence interval of $95 \%$ was used.

\section{Results and discussion}

The effects of saccharification and fermentation time of OPMF on the growth of probiotic L. rhamnosus GR-1 are as shown in Table 1. Based on the results, the individual effect of saccharification time on $L$. rhamnosus GR-1 growth showed a significant $(\mathrm{p}<0.05)$ increase in $\mathrm{OD}_{600}$ from saccharification time of 1 to 3 hrs. However, further increase of saccharification time from 3 to $6 \mathrm{hrs}$ did not show any significant change in the growth of L. rhamnosus GR-1. The significant increase in growth of L. rhamnosus GR-1 $(\mathrm{p}<0.05)$ showed that saccharified OPMF was able to support the growth of probiotic bacteria.

The increase in growth from 1 to $3 \mathrm{hrs}$ of saccharification time may be due to the ease in using the substrate as the longer duration of saccharification will result in a lower degree of GU of the cellulose in OPMF (Meng et al., 2016). However, saccharification beyond 3 
hrs may not have produced any further decrease in the $\mathrm{GU}$ of cellulose thus resulting in the insignificant growth measured. Results from Table 2 supported the mentioned possibility as it can be seen that the type of oligosaccharide after 3 and $6 \mathrm{hrs}$ of saccharification (1, 2, 3 and 4 glucose units) were higher compared to $1 \mathrm{hr}$ (1 and 2 glucose units). In addition, no increase in the type of oligosaccharide was observed between 3 and 6 hrs of saccharification.

Table 1. Individual and interactive effects of saccharification time and fermentation time based on two-way ANOVA for the growth of Lactobacillus rhamnosus GR-1 using oil palm mesocarp fibre as carbon source.

\begin{tabular}{ccc}
\hline Effects & Mean of $\mathrm{OD}_{600}$ & $\mathrm{p}$ \\
\hline \multicolumn{3}{c}{ Saccharification time (hrs) } \\
\hline 1 & $0.315^{\mathrm{b}}$ & 0.008 \\
3 & $0.562^{\mathrm{a}}$ & \\
6 & $0.515^{\mathrm{a}}$ & \\
\hline \multicolumn{3}{c}{ Fermentation time (hrs) } \\
\hline 0 & $0.038^{\mathrm{c}}$ & $<0.001$ \\
12 & $0.832^{\mathrm{a}}$ & \\
24 & $0.522^{\mathrm{b}}$ & \\
\hline
\end{tabular}

Interaction 0.028

Values are presented as mean. Values with different superscript within the same saccharification time or fermentation time are significantly different $(\mathrm{p}<0.05)$.

Table 2. The number of glucose units for OPMF cellulose oligosaccharide at different saccharification time and FOS as carbon source.

\begin{tabular}{cc}
\hline Samples & Number of glucose units (GU) \\
\hline OPMF (1hr) & 1,2 \\
OPMF (3hrs) & $1,2,3,4$ \\
OPMF (6hrs) & $1,2,3,4$ \\
FOS & 3-Sep \\
\hline
\end{tabular}

A previous study reported that L. rhamnosus GR-1 grew on $\beta$-glucan oligosaccharides where it consistently consumed mono- and disaccharides and preferentially consumed tri-saccharides (degree of polymerisation (DP) 3) (Sims et al., 2014). Several studies have described that L. rhamnosus consumed both oligosaccharides (tri- and disaccharides) as well as glucose as reported in a study on the consumption of Oligomate 55 (galactooligosaccharide 55\%) in fermentation media (Figueroa-Gonzalez et al., 2019).

Table 1 also shows a significant individual effect $(\mathrm{p}<0.05)$ of fermentation time on the growth of $L$. rhamnosus GR-1. An increase in fermentation time from 0 to $12 \mathrm{hrs}$ resulted in a significant increase $(\mathrm{p}<0.05)$ in the growth of L. rhamnosus GR-1. However, a further increase from 12 to $24 \mathrm{hrs}$ showed a significant decrease $(p<0.05)$ in the growth of the probiotic bacteria. In general, the longer the fermentation time, the higher the opportunity for the bacteria to consume the saccharified
OPMF (Hawashi et al., 2017). Thus, this explained the significant increase $(\mathrm{p}<0.05)$ in growth when fermentation time was increased to $12 \mathrm{hrs}$. The decrease in growth when fermentation time was extended to 24 hrs may be due to the limitation of nutrients to support growth (Hawashi et al., 2017).

The significant interaction between saccharification time and fermentation time as shown in Table 1 is elaborated in Table 3. The effect of increased saccharification time was dependent on fermentation time where at fermentation time of $12 \mathrm{hrs}$, growth of $L$. rhamnosus GR-1 increased significantly $(\mathrm{p}<0.05)$ from 1 to $3 \mathrm{hrs}$ but not significantly different when further increased to $3 \mathrm{hrs}$. Similarly, the interactive effect between saccharification time and fermentation time can be observed for saccharification time of $6 \mathrm{hrs}$ where the increase in fermentation time from 12 to $24 \mathrm{hrs}$ resulted in a significant decrease $(p<0.05)$ in bacterial growth.

Table 3 also shows the combined effects of saccharification time and fermentation time compared to FOS. FOS samples showed a similar trend for growth to OPMF 1 and 3 hrs where there was a significant increase $(\mathrm{p}<0.05)$ when fermentation time was increased from 0 to $12 \mathrm{hrs}$. Increasing fermentation time from 12 to $24 \mathrm{hrs}$ did not produce any significant difference in growth. Thus, OPMF samples showed similar growth compared to FOS suggesting the possible potential of OPMF as a prebiotic material. However, further studies need to be carried out to ascertain the potential.

Table 3. Combined effect of saccharification time and fermentation time on the growth of Lactobacillus rhamnosus GR-1 using oil palm mesocarp fibre as carbon source.

\begin{tabular}{cccc}
\hline \multirow{2}{*}{ Sample } & \multicolumn{3}{c}{ Fermentation time (hrs) } \\
\cline { 2 - 4 } & 0 & 12 & 24 \\
\hline Negative control & $0.015^{\mathrm{i}}$ & $0.625^{\mathrm{def}}$ & $0.320^{\mathrm{fgh}}$ \\
(No sugar) & $0.055^{\mathrm{ghi}}$ & $0.510^{\mathrm{def}}$ & $0.380^{\mathrm{efg}}$ \\
OPMF 1 hr & $0.050^{\mathrm{ghi}}$ & $0.945^{\mathrm{abc}}$ & $0.690^{\mathrm{cde}}$ \\
OPMF 3 hrs & $0.010^{\mathrm{j}}$ & $1.040^{\mathrm{ab}}$ & $0.495^{\mathrm{def}}$ \\
OPMF 6 hrs & $0.015^{\mathrm{j}}$ & $0.810^{\mathrm{bcd}}$ & $0.530^{\text {def }}$ \\
\hline
\end{tabular}

Values with different superscript within the same row are significantly different $(\mathrm{p}<0.05)$.

The combined effect of saccharification time and fermentation time on $\mathrm{pH}$ during the growth of $L$. rhamnosus GR-1 using oil palm mesocarp fibre as carbon source was analysed as shown in Table 4. Comparison made among the samples showed that for saccharification time of 1, 3 and $6 \mathrm{hrs}$, fermentation up to 12 hrs showed a significant $(\mathrm{p}<0.05)$ decrease in $\mathrm{pH}$. However, all OPMF samples (1, 3, and $6 \mathrm{hrs}$ ) did not show any significant changes $(\mathrm{p}>0.05)$ in $\mathrm{pH}$ after a further increase in fermentation time from 12 to $24 \mathrm{hrs}$. The trend showed for $\mathrm{pH}$ (Table 4) corroborated the trend of $\mathrm{OD}_{600}$ representing the growth of L. rhamnosus 
GR-1 as shown in Table 3. According to Sims et al. (2014), an increase in $\mathrm{OD}_{600}$ of the culture broth and a decrease in $\mathrm{pH}$ of the culture media is the result of shortchain fatty acid production and reflected the ability of the bacteria to grow on the substrates. It has also been reported that L. rhamnosus is able to increase the production of SCFAs such as acetate, propionate and butyrate (Leblanc et al., 2017). Thus, these observations further support the ability of the probiotic L. rhamnosus to grow on saccharified OPMF.

Table 4. Combined effect of saccharification time and fermentation time on $\mathrm{pH}$ during growth of Lactobacillus rhamnosus GR-1 using oil palm mesocarp fibre as carbon source.

\begin{tabular}{cccc}
\hline \multirow{2}{*}{ Sample } & \multicolumn{3}{c}{ Fermentation time (hrs) } \\
\cline { 2 - 4 } & 0 & 12 & 24 \\
\hline Negative control & $6.703^{\mathrm{ab}}$ & $6.830^{\mathrm{a}}$ & $6.857^{\mathrm{a}}$ \\
(No sugar) & $6.410^{\mathrm{ab}}$ & $5.480^{\mathrm{cd}}$ & $5.537^{\mathrm{c}}$ \\
OPMF 1 hr & $6.390^{\mathrm{ab}}$ & $5.257^{\mathrm{d}}$ & $5.277^{\mathrm{d}}$ \\
OPMF 3 hrs & $6.363^{\mathrm{ab}}$ & $5.197^{\mathrm{d}}$ & $5.137^{\mathrm{d}}$ \\
OPMF 6 hrs & $6.187^{\mathrm{b}}$ & $6.230^{\mathrm{b}}$ & $6.533^{\mathrm{ab}}$ \\
\hline
\end{tabular}

Values with different superscript within the same row are significantly different $(\mathrm{p}<0.05)$.

The results obtained (Table 4) also revealed that during fermentation for $12 \mathrm{hrs,}$ an increase in saccharification time from 1 to $3 \mathrm{hrs}$, and subsequently to $6 \mathrm{hrs}$ did not result in any significant $(\mathrm{p}>0.05)$ changes in $\mathrm{pH}$ for the growth of L. rhamnosus GR-1. However, when fermentation was extended for $24 \mathrm{hrs}$, OPMF saccharified for $3 \mathrm{hrs}$ resulted in a significantly $(\mathrm{p}<0.05)$ decreased culture medium $\mathrm{pH}$ compared to OPMF $1 \mathrm{hr}$. Further increase in saccharification time from 3 to $6 \mathrm{hrs}$ did not show any significant $(\mathrm{p}>0.05)$ difference in $\mathrm{pH}$. The results suggested that an extended fermentation time was needed to realise the effects of increased saccharification time on $\mathrm{pH}$.

Compared to FOS samples, the pH of all OPMF samples (1, 3 and $6 \mathrm{hrs}$ ) showed significantly lower $(\mathrm{p}<0.05) \mathrm{pH}$ after fermentation for 12 and $24 \mathrm{hrs}$. As the lowering of $\mathrm{pH}$ may have been attributed to the production of short-chain fatty acids (Sim et al., 2014), the results suggested that saccharified OPMF may be able to produce more short-chain fatty acid by $L$. rhamnosus compared to FOS.

\section{Conclusion}

In our study, both saccharification time and fermentation time with $3 \mathrm{hrs}$ and $12 \mathrm{hrs}$, respectively, showed a significant $(\mathrm{p}<0.05)$ effect on the growth of $L$. rhamnosus GR-1 using saccharified oil palm mesocarp fibre (OPMF) as carbon sources. The growth of $L$. rhamnosus GR-1 using OPMF was comparable to its growth when using FOS. In addition, the growth of $L$. rhamnosus GR-1 using OPMF saccharified for $3 \mathrm{hrs}$ resulted in a significantly $(\mathrm{p}<0.05)$ decreased culture medium $\mathrm{pH}$ compared to FOS. Thus, this work suggested that saccharifying OPMF to oligosaccharides has the potential to be developed as a prebiotic for L. rhamnosus GR-1 probiotic.

\section{Conflict of interest}

The authors declare no conflict of interest.

\section{Acknowledgments}

The authors would like to express their gratitude to the Ministry of Higher Education Malaysia for the financial support through the Fundamental Research Grant Scheme (FRGS) (FRGS/1/2016/STG03/ $\mathrm{UKM} / 02 / 6)$.

\section{References}

Asmariah, A., Yap, W.B., Kofli, N.T. and Ghazali, A.R. (2018). Probiotic potentials of Lactobacillus plantarum isolated from fermented durian (Tempoyak), a Malaysian traditional condiment. Food Science and Nutrition, 6(6), 1370-1377. https:// doi.org/10.1002/fsn3.672

Dávila, I., Gullón, B., Alonso, J.L., Labidi, J. and Gullón, P. (2019). Vine shoots as new source for the manufacture of prebiotic oligosaccharides. Carbohydrate Polymers, 207, 34-43. https:// doi.org/10.1016/j.carbpol.2018.11.065

Dunkley, K.E. and Hekmat, S. (2019). Development of probiotic vegetable juice using Lactobacillus rhamnosus GR-1. Nutrition and Food Science, 50(5), 955-968. https://doi.org/10.1108/NFS-06-2019-0192

Figueroa-Gonzalez, I., Rodriguez-Serrano, G., GomezRuiz, L., Garcia-Garibay, M. and Cruz-Guerrero, A. (2019). Prebiotic effect of commercial saccharides on probiotic bacteria isolated from commercial products. Food Science and Technology (Campinas), 39(3), 747-753. https://doi.org/10.1590/fst.07318

Gullon, P., Gullon, B., Moure, A., Alonso, J.L., Domingues, H. and Parajó, J.C. (2009). Manufacture of Prebiotics from Biomass Sources. In Charalampopoulos, D. and Rastall, R.A. (Eds). Prebiotics and Probiotics Science and Technology, p. 535-589. USA: Springer. https://doi.org/10.1007/978 -0-387-79058-9_14

Hassan, O., Tang, P.L., Maskat, M.Y., Illias, R.M., Badri, K., Jahim, J. and Mahadi, N.M. (2013). Optimization of pretreatments for the hydrolysis of oil palm empty fruit bunch fiber (EFBF) using 
enzyme mixtures. Biomass and Bioenergy, 56, 137146. https://doi.org/10.1016/j.biombioe.2013.04.021

Hawashi, M., Ningsih, T.S., Cahyani, S.B.T., Widjaja, K.T. and Gunawan, S. (2018). Optimization of the fermentation time and bacteria cell concentration in the starter sulture for cyanide acid removal from wild cassava (Manihot glaziovii). MATEC Web of Conferences, 156, 01004. https://doi.org/10.1051/ matecconf $/ 201815601004$

Jalaludin, I., Sudin, A.H., Said, I. M., Azizan, K.A., Baharum, S.N., Murad, A.M.A., Bakar, F.D.A., Mahadi, N.M., Wormald, M.R. and Alonzi, D.S. (2017). Fluorescence and evaporative light scattering HPLC profiling of intracellular asparagine $(N)$ linked oligosaccharides from Saccharomyces cerevisiae using the alg8 mutant. Malaysian Journal of Analytical Sciences, 21(6), 1210-1218. https:// doi.org/10.17576/mjas-2017-2106-01

Kunova, G., Rada, V., Lisova, I., Ročková, Š. and Vlkova, E. (2012). In vitro fermentability of prebiotic oligosaccharides by lactobacilli. Czech Journal of Food Sciences, 29, S49-S54. https:// doi.org/10.17221/306/2011-CJFS

Leblanc, J.G., Chain, F., Martín, R., BermúdezHumarán, L.G., Courau, S. and Langella, P. (2017). Beneficial effects on host energy metabolism of short-chain fatty acids and vitamins produced by commensal and probiotic bacteria. Microbial Cell Factories, 16(1), 1-10. https://doi.org/10.1186/ s12934-017-0691-z

Malaysian-German Chamber of Commerce and Industry (MGCC). (2018). Oil palm biomass and biogas in Malaysia (2017). Kuala Lumpur, Malaysia: EUMalaysia Chamber of Commerce and Industry (EUMCCI).

Meng, X., Yoo, C.G., Li, M. and Raguskas, A.J. (2016). Physicochemical structural changes of cellulosic substrates during enzymatic saccharification. Journal of Applied Biotechnology and Bioengineering, 1(3), 97- 84. https://doi.org/10.15406/jabb.2016.01.00015

Mueller, M., Reiner, J., Fleischhacker, L. Viernstein, H., Loeppert, R. and Praznik, W. (2016). Growth of selected probiotic strains with fructans from different sources relating to degree of polymerization and structure. Journal of Functional Foods, 24, 264-275. https://doi.org/10.1016/j.jff.2016.04.010

Nguyen, T.H. and Haltrich, D. (2013). Microbial production of prebiotic oligosaccharides. In McNeil, B., Archer, D., Giavasis, I. and Harvey, L. (Eds). Microbial Production of Food Ingredients, Enzymes and Nutraceuticals, p. 494-530. USA: Elsevier. https://doi.org/10.1533/9780857093547.2.494
Nordin, N.I.A., Ariffin, H., Andou, Y., Hassan, M.A., Shirai, Y., Nishida, H., Yunus, W.M.Z.W., Karuppuchamy, S. and Ibrahim, N.A. (2013). Modification of oil palm mesocarp fiber characteristics using superheated steam treatment. Molecules, 18(8), 9132-9146. https:// doi.org/10.3390/molecules18089132

Pasma, S.A., Rusli, D. and Maskat, M.Y. (2019). Enzymatic synthesis of biodegradable polyesters using succinic acid monomer derived from cellulose of palm empty fruit bunch. Journal of Wood Chemistry and Technology, 38(6), 445-459. https:// doi.org/10.1080/02773813.2018.1533976

Pasma, S.A., Rusli, D., Maskat, M.Y. and Hassan, O. (2013). Application of Box-Behnken design in optimization of glucose production from oil palm empty fruit bunch cellulose. International Journal of Polymer Science, 2013, 104502. https:// doi.org/10.1155/2013/104502

Pasma, S.A., Rusli, D., Suria, R., Maskat, M.Y. and Zulfakar, M.H. (2019). Enzymatic degradation of lignin extracted from oil palm empty fruit bunch using laccase and cutinase. Bioresources, 14(4), 8879-8891.

Patel, S. and Goyal, A. (2011). Functional oligosaccharides: production, properties and applications. World Journal of Microbiology and Biotechnology, 27(5), 1119-1128. https:// doi.org/10.1007/s11274-010-0558-5

Roberfroid, M., Gibson, G.R., Hoyles, L., Mccartney, A.L., Rastall, R., Rowland, I., Wolvers, D., Watzl, B., Szajewska, H. and Stahl, B. (2010). Prebiotic effects: metabolic and health benefits. British Journal of Nutrition, 104(S2), S1-S63. https:// doi.org/10.1017/S0007114510003363

Shamsudin, W.N.F., San, L.S., Wan, H.Y., Abdullah, N., Saad, W.Z. and Wan, K.L. (2019). Probiotic properties of Lactobacillus isolates from chicken intestines. Journal of Biochemistry, Microbiology and Biotechnology, 7(2), 8-13.

Shi, Y., Liu, J., Yan, Q., You, X., Yang, S. and Jiang, Z. (2018). In vitro digestibility and prebiotic potential of curdlan (1-3)- $\beta$-D-glucan oligosaccharides in Lactobacillus species. Carbohydrate Polymers, 188, 17-26. https://doi.org/10.1016/j.carbpol.2018.01.085

Sims, I.M., Ryan, J.L. and Kim, S.H. (2014). In vitro fermentation of prebiotic oligosaccharides by Bifidobacterium lactis HN019 and Lactobacillus spp. Anaerobe, 25, 11-17. https://doi.org/10.1016/ j.anaerobe.2013.11.001

Srivastava, N., Rathour, R., Jha, S., Pandey, K., Srivastava, M., Thakur, V.K., Sengar, R.S., Gupta, 
V.K., Mazumder, P.B. and Khan, A.F. (2019).

Microbial beta glucosidase enzymes: recent advances in biomass conversation for biofuels application. Biomolecules, 9(6), 9060220. https:// doi.org/10.3390/biom9060220

Tang, P.L., Peer, M.A., Engliman, N.S. and Hassan, O. (2018). Effects of pretreatment and enzyme cocktail composition on the sugars production from oil palm empty fruit bunch fiber (OPEFBF). Cellulose, 25(8), 4677-4694. https://doi.org/10.1007/s10570-018-1894 $-0$

Westerik, N., Kort, R., Sybesma, W. and Reid, G. (2018). Lactobacillus rhamnosus probiotic food as a tool for empowerment across the value chain in Africa. Frontiers in Microbiology, 9, 1501. https:// doi.org/10.3389/fmicb.2018.01501

White, J. and Hekmat, S. (2018). Development of probiotic fruit juices using Lactobacillus rhamnosus GR-1 fortified with short chain and long chain inulin fiber. Fermentation, 4(2), 4020027. https:// doi.org/10.3390/fermentation4020027

Williams, M. and Hekmat, S. (2017). Lactobacillus rhamnosus GR-1 in Fermented Rice Pudding Supplemented with Short Chain Inulin, Long Chain Inulin, and Oat as a Novel Functional Food. Fermentation, 3(4), 3040055. https:// doi.org/10.3390/fermentation3040055

Woon, J.S.K., Mackeen, M.M., Bin Sudin, A.H., Mahadi, N.M., Illias, R.M., Murad, A.M.A. and Bakar, F.D.A. (2016). Production of an oligosaccharide-specific cellobiohydrolase from the thermophilic fungus Thielavia terrestris. Biotechnology Letters, 38(5), 825-832. https:// doi.org/10.1007/s10529-016-2045-z

Zare, F., Orsat, V., Champagne, C., Simpson, B.K. and Boye, J.I. (2012). Microbial and physical properties of probiotic fermented milk supplemented with lentil flour. Journal of Food Research, 1(1), 94-109. https://doi.org/10.5539/jfr.v1n1p94 